\title{
Experimental Study of the Effect of Catalyst Properties on Hydrodynamics and Mass Transfer in a Slurry Reactor
}

\author{
Hiba M. Abdullah, Mohammad F. Abid, Orooba N. Abdullah \\ Department of Chemical Engineering, University of Technology \\ 80025@uotechnology.edu.iq
}

\begin{abstract}
This work was devoted to study the influence of wellknown catalyst carriers (activated utilized in catalytic reactions carbon and silica) on the hydrodynamic parameters and mass transfer rate in a slurry reactor. The influence of silica and activated carbon particles concentration up to $20 \% \mathrm{v} / \mathrm{v}$ on regime transition, average gas holdup, mass transfer coefficient, and $\mathrm{CO}_{2}$ removal was studied in a semi- batch slurry bubble column reactor (SBC) with a porous gas sparger. The effects of hydrophobicity and surfactant were also investigated. It was concluded the gas holdup is reduced and the point of transition from laminar to turbulent regime is shifted to less gas velocity when the hydrophobic and hydrophilic particles concentration was larger than $3 \%(\mathrm{v} / \mathrm{v})$. The Particle hydrophobicity, gas velocity, and electrolyte concentration have positive impacts on gas holdup while slurry concentration gave a different trend. Experimental results show that the optical fiber probe is valid to use in a slurry bubble column and can also generate useful data such as bubble rise velocity and bubble distribution. The optical fiber probe was proved to be good technique for estimation of volumetric mass transfer coefficient within an error of $\pm 18 \%$. Mass transfer experiments with gaseous $\mathrm{CO}_{2}$ showed a behavior of removal in the same trend of increasing gas holdup with gas velocity. A noticeable removal of gaseous pollutants was observed for non-wettable particles at solid loading of $3 \% \mathrm{v} / \mathrm{v}$.

Mathematical correlations were formulated for $\mathrm{CO}_{2}$ removal as function of studied operating variables with correlation factors of 0.95-0.98. The present study depicts the effect of catalyst carrier on the hydrodynamic characteristics and mass transfer in a slurry reactor.
\end{abstract}

Keywords: Slurry reactor; catalyst support; Hydrodynamics; particle hydrophobicity; Optical fibers; mass transfer coefficient; $\mathrm{CO}_{2}$ removal.

Paper History: (Received 2-9-2018; Accepted :14-22019).

\section{Introduction}

One of the most alarms in global environmental problems today is the increase in the global temperature. This problem caused by increasing the concentration of some gases pollutants (e.g., $\mathrm{CO}_{2}$ and $\mathrm{CH}_{4}$ ) from many industrial plants. To minimize and control this effect an efficient improvement must be carried out to the absorption and reaction systems (Babadi, 2005). The slurry bubble column is used in the chemical process industries as absorbers or reactors. They are typically applied to hydrogenation, chlorination, sulfonation-reaction, FisherTropsch synthesis or utilized as absorbers of environmental gaseous pollutants. Slurry bubble columns are used extensively in chemical industries for different processes. It is operated either in continuous or semibatch mode. Herbolzheimer and Enrique, 2006 reported that slurry bubble columns have many benefits over fixed bed column. They have higher mass and heat transfer coefficients and as catalytic reactor, the catalysts used have higher service life. The hydrodynamics in a gasliquid or gas-liquid-solid reactor are characterized by different flow regimes, mainly, the homogeneous transition, and heterogeneous regimes. The industrial interest for most processes is in the heterogeneous flow regime (Hyndman et al., 1997; Krishna et al., 1997). It is therefore extremely important to understand the different hydrodynamics regimes for the purpose of reactor design, operation, control, and scale-up. One of the approaches to identify the boundaries of the bubbly-transition-turbulent regimes is based on a sharp variation of the gas holdup (Zahradink and Fialova, 1996) or the drift flux (Zuber and Findlay, 1965; Vial et al., 2002) with respect to the superficial gas velocity. The dominate conditions that influence the hydrodynamics and mass and heat transfer behaviors include the superficial gas velocity, pressure, temperature, solid concentration and gas distribution. The superficial gas velocity is a dominate factor that affects the gas holdup, and numerous experimental studies have been reported (Krishna et al., 1997; Degaleesan et al., 2001, Wang et al., 2004, Shaikh and Al-Dahhan, 2005). Electrolyte, salt, or system contaminants may exist inadvertently in slurry bubble columns in real industrial application. Hikita et al., 1980; Sada et al., 1984 investigated the effect of surfactants on gas holdup in slurry bubble column. They reported that the presence of surfactants or any contaminants in the continuous phase of the slurry bubble column have positive effect on gas holdup. Ruzicka et al., 2005 reported that in spite of all the efforts aimed at the gas holdup studies, the information about the effect of solids on the flow regimes is very scarce and often, no attempt is made to specify the prevailing flow regime during the experiment. The 
hydrophobic/hydrophilic characteristic of solids is known to play a key role in many processes such as: wetting, flotation, enhanced oil recovery, cleaning technologies, supper-hydrophobicity, liquid spreading, etc.

Jamialahmadi and Muller, 1991 reported that the nature of solids, which added to a gas-liquid system in a column, strongly affects the gas holdup in the system. Therefore, the influence of solids nature on the velocity of transition needs to study (Sheikh and Al-Dahhan, 2007).

Abid et al., 2012 reported that hydrophilic particles could be converted to hydrophobic ones by surface treatment with hydrophobic aliphatic alcohols. It is well-known that the interfacial area and mass transfer coefficient are regarded as influential factors in bubble column sizing. Wilkinson et al., 1992 studied the effect of

bubble coalescence and breakup on the mass transfer in two-phase bubble column. The authors depicted that the distribution of bubbles size and hydrodynamic characteristics play a remarkable role on bubble column reactor design. Different techniques have been used for bubble size estimation, Ueyama et al., 1980 used photographic method, Fukuma et al., 1987 used electroresistivity method, Letzel et al., 1999 used opticalfiber method and the chemical-absorption method. Liu et al., 2003 (a, b) used optical fiber probe to determine solid concentration, bubble sizes, bubble size distribution, and bubble velocities in fluidized bed column. The authors reported that the optical fiber probes characterized by simplicity, cost effective, and accurate responses. Jiang et al. (1995) used the PIV technique to acquire the characteristics of bubbles (shapes and sizes). The goal of the present work was to increase the fundamental knowledge on the behavior of particle-to-bubble interactions in relationship to the physical properties of the catalyst particles, such as catalyst hydrophobicity, and catalyst concentration in slurry bubble columns. These investigations must be combined with the hydrodynamics of slurry bubble column i.e., gas hold-up, flow regimes and regime transitions and solid distribution. It is also the aim of the present study to investigate the effect of solid properties on mass transfer coefficient and removal of environmental gaseous pollutants in a slurry reactor.

\section{Theoretical Aspects}

\section{Gas holdup}

In this study, the gas flow velocities have range of variation (from $1 \mathrm{~cm} / \mathrm{s}$ to $10 \mathrm{~cm} / \mathrm{s}$ ) which scanned the different flow regimes. The percentage average gas holdup was estimated by using Equation (1) (Shah et al., 1982)

$$
\varepsilon_{\mathrm{g}}=\frac{\left(\mathrm{H}_{\mathrm{D}}-\mathrm{H}_{\mathrm{L}}\right)}{\mathrm{H}_{\mathrm{D}}} * 100
$$

Where $H_{D}$ : the aerated height of liquid

$$
\mathrm{H}_{\mathrm{L}} \text { : Static height of liquid }
$$

\section{Critical values}

To determine definitive values of both gas holdup and superficial gas velocity, we followed the approach that had been commonly used in identifying the prevailing flow regime which is based on the concept of the driftflux model, suggested by (Zuber and Findlay, 1964) and is identified in Equation (2) as follows:

$$
\frac{\mathrm{u}_{\mathrm{g}}}{\mathrm{v}_{\mathrm{g}}}=\mathrm{C}_{0}\left(\mathrm{u}_{\mathrm{g}} \pm \mathrm{u}_{1}\right)+\mathrm{C}_{1}
$$

$$
c_{0}=\frac{\left\langle\varepsilon_{g}\left(u_{g} \pm u_{l}\right)\right\rangle}{\left\langle\varepsilon_{g}\right)\left(\left(u_{g} \pm u_{i}\right)\right\rangle}
$$

Where $\mathrm{C}_{0}$ is a factor linked to the holdup uniformity of gas at radial direction.

$$
\mathrm{C}_{1}=\frac{\left\langle\mathrm{j}_{\mathrm{gl}}\right\rangle}{\left\langle\varepsilon_{\mathrm{g}}\right\rangle}
$$

Where $\mathrm{C} 1$ is a factor linked to the rise velocity of bubble.

The alteration of $\mathrm{C}_{0}$ with $\mathrm{u}_{\mathrm{g}}+\mathrm{u}_{1}$ could be utilized to characterize the transition of the flow regime as shown by (Zuber and Findlay,1964),

Where $\mathrm{u}_{\mathrm{g}} / \varepsilon_{\mathrm{g}}$ was plotted versus $\mathrm{u}_{\mathrm{g}}$ (in batch liquid mode).

$\mathrm{u}_{\mathrm{g}} / \varepsilon_{\mathrm{g}} \quad$ was identified as the bubble swarm velocity (Krishna, 2000).

\section{Mass Transfer Coefficient}

Fan and Tsuchiya (1990) offered graphs of bubble shapes denoting all conditions of operation, oblate ellipsoidal bubbles were formed. To estimate the coefficient of mass transfer of liquid per unit volume, Nedeltchev \& Schumpe (2007) proposed an accurate correlation for ellipsoidal bubbles by the following formula:

$\mathrm{k}_{\mathrm{La}}=\mathrm{f}_{\mathrm{c}} \sqrt{\frac{\mathrm{AD}_{\mathrm{L}} \mathrm{R}_{\mathrm{gf}}}{\pi \mathrm{S}_{\mathrm{B}}}} \frac{f_{B} \cdot s_{B}}{A \cdot u_{B}}$

Where $R_{s f}$ is the formulation rate for bubble surface of oblate ellipsoidal shape (Nedeltchev et al., 2006a \& b).

$$
\mathrm{R}_{\mathrm{sf}}=\pi \mathrm{u}_{\mathrm{g}}\left[\sqrt{\frac{1^{2}+\mathrm{h}^{2}}{2}}-\sqrt{\frac{(1-\mathrm{h})^{2}}{s}}\right]
$$

$f_{c}$ is a correction factor introduced by (Nedeltchev \& Schumpe, 2007) accounts for the influence of the bubble wake and disturbance of surface. 


$$
\mathrm{f}_{\mathrm{c}}=0.124 \mathrm{E}_{\mathrm{O}}^{\mathrm{Q} .04}\left[\frac{\mathrm{Pg}}{\mathrm{pgref}}\right]^{0.15}
$$

$f_{B}$, and $S_{B}$ are bubble formation frequency and bubble surface respectively.

$\mathrm{D}_{\mathrm{L}}$ is the molecular diffusivity of solute into liquid solution estimated using Wilke and Chang correlation (Reid and Sherwood, 1977).

$\mathrm{u}_{\mathrm{B}}$ is the bubble rise velocity which is estimated using eqn. 6 (Mainland and Welty, 1995).

$$
\mathrm{u}_{\mathrm{B}}=\frac{\mathrm{L}_{\mathrm{s}} \mathrm{ff}}{\tau}
$$

Where $\mathrm{L}_{\text {eff }}$ is the effective distance between the bottom and top detecting fibers and $\mathrm{T}$ is the delay time of the signals.

Chan et al. (1987) correlated the bubble size with the estimated bubble length $(l)$ as,

$$
\mathrm{d}_{\mathrm{b}}=1.43 * 1
$$

For calculating volumetric liquid-side mass transfer coefficient experimentally, an equation developed by Vandu and Krishna (2003) based on two film theory was used:

$$
\frac{C_{L}}{C_{L}^{*}}=1-\exp \left[-\frac{k_{L a}}{1-\varepsilon_{g}} t\right]
$$

The only unknown constant in equation (8) is $\mathrm{k}_{\mathrm{L} . \mathrm{a}}$, which can be determined by a regression of equation (8) to the actual concentration data. With the aid of statistics program, equation (8) can be solved to find $\mathrm{k}_{\mathrm{L}} \mathrm{a}$.

\section{Materials and Methods}

Schematic plot of the experimental set up is seen in Figure 1. The column is made of Plexiglas with inside diameter $0.13 \mathrm{~m}$ and height of $1.5 \mathrm{~m}$. The column had (4) sample ports located -equally spaced-along the column height. An oil-free compressor (Model: V-0.12/8, $0.8 \mathrm{MPa}, 100 \mathrm{~L} / \mathrm{min}$ from Shimge Co.) was employed to supply air to the column. Air is introduced through $90 \mu \mathrm{m}$ porous sparger made of ceramic material and its flow rate is maintained using a calibrated air rotameter (Type: Roteck, Range: 0-100L/min). Distilled water with $0.15 \mathrm{M}$ $\mathrm{NaCl}$ solution was used as liquid phase. The liquid was confined into the column (no liquid throughput) and the clear liquid height was $0.9 \mathrm{~m}$ for all experiments. The effect of the particles hydrophobicity is studied by using, two catalyst carriers silica and carbon which commonly used in catalyzed reactors. The solid loading range studied is $(0-20 \% \mathrm{v} / \mathrm{v})$.
Experiments for mass transfer coefficient were carried out using a compressed bottle of $\mathrm{CO}_{2}$ and a dual fiber-optical probe system as shown in Figure 1. For accurate measurements of bubble size and velocity, two homemade optical fiber probes (OFP) shown in Figure (2a), based on the design utilized by Chabot et al. (1992), are going to be used with the tip of probe located at $1 / 3$ of the size of the slurry bed. In this system, bubble size and velocity measurements are obtained by correlation of voltage measurements at both OFPs. Optical probe selected was based on backscattering principle, with diameters of the fiber larger than the particle size. The measuring system showed in Figure (2-b), consists of an emitter which is illuminated by $750 \mathrm{~nm}$ LED, a receiver with phototransister, a passive splitter used for monitoring purposes, a RIFOCS power meter, and a data acquisition system in the PC. When particles in the slurry move facing the probe, most of the released light is being inverted and the phototransistor responds with a high current, which is converted to a voltage signal at a resistance. On the contrary, when a gas bubble passes, small fraction of light is reflected back to the probe and a low signal voltage is observed. Bubbles going through both optical fiber probes can be analyzed for determining its velocity and length. When the velocity and the time it takes the bubble to cross each probe is known, bubble length can also be obtained. The signal revealed on each fiber was monitored with a digital oscilloscope (Model DS1052E, Rigol).

To investigate effects of the solid particles (hydrophobic and hydrophilic) on the absorption rate of $\mathrm{CO}_{2}$ in the slurry reactor, a pure gaseous $\mathrm{CO}_{2}$ was used with $0.15 \mathrm{M}$ electrolyte - water mixture. Mass transfer study was carried out in the Plexiglas column shown in Figure 1, with different superficial gas velocities and solid loadings. Temperature of the mixture is kept approximately constant at $25^{\circ} \mathrm{C}$ with a deviation of $\pm 1^{\circ} \mathrm{C}$. Samples from each run was taken after $1 \mathrm{hr}$, to reach steady-state conditions in the bulk of liquid. When $\mathrm{CO}_{2}$ is absorbed into water a carbonate ion is formed. The rate of reduction of $\mathrm{CO}_{2}$ is proportional to the concentration of hydroxyl ion (Pinset et al., 1956).

\section{$\mathrm{CO}_{2}+\mathrm{OH}^{-} \rightarrow \mathrm{HCO}_{3}^{-}$}

The concentration of carbonate ion was quantitatively identified by titration the sample against $0.5 \mathrm{M} \mathrm{NaOH}$ solution.

The physical properties of solid particles and fluids used are given in Table 1 and Table 2 respectively. 


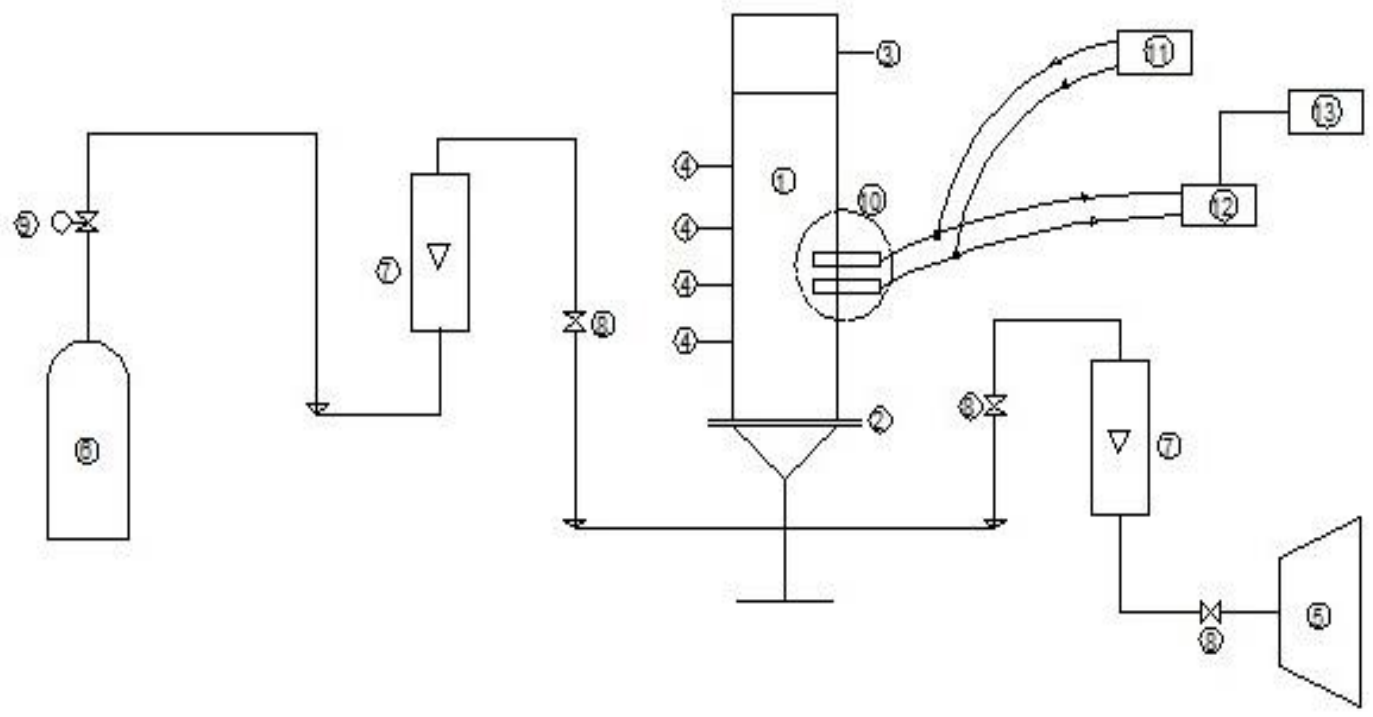

Figure (1) Experimental setup

1-slurry bubble column, 2- porous gas sparger, 3- pressure taps, 4- sampling ports, 5- Oil-free air compressor, 6- $\mathrm{CO}_{2}$ bottle, 7- Calibrated gas rotameter, 8- needle valves, 9- pressure regulator, 10- two parallel oriented optical fiber probes, 11-emitter, 12- receiver, 13- aquisitition system with PC.

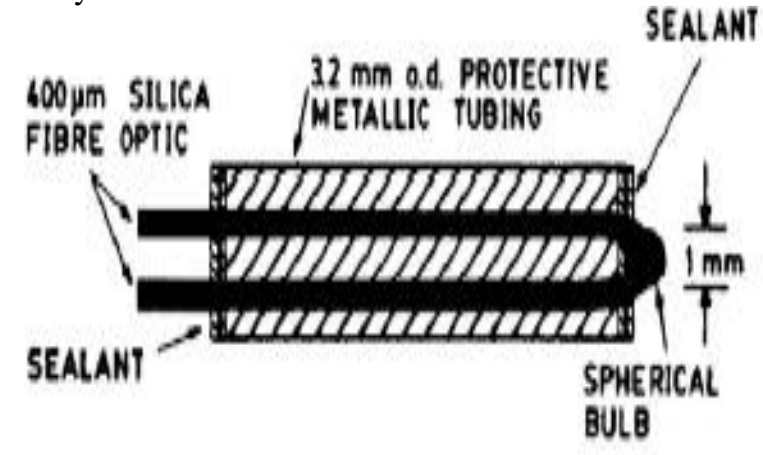

(a)

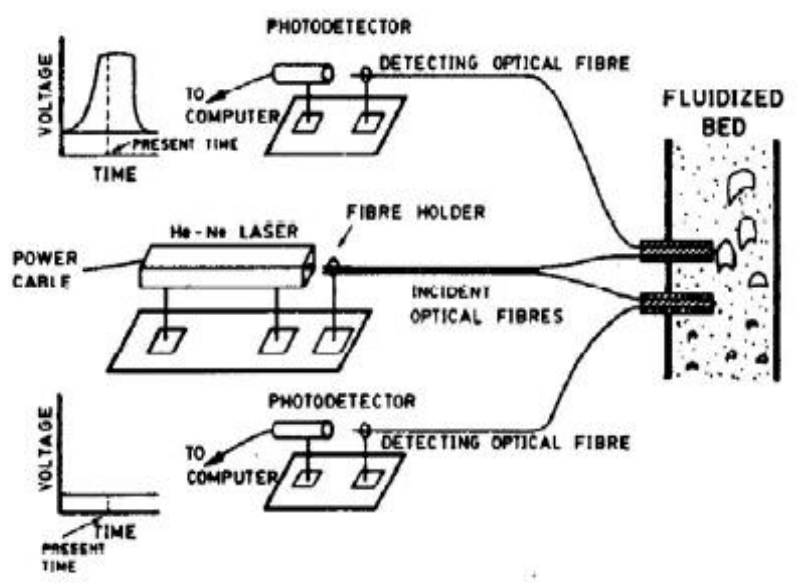

(b)

Figure (2) a- cross sectional view of the optical probe, b- schematic diagram of the optical probe operating system. (Chabot et al, 1992) 
Table 1 Physical properties of the catalyst support used in the present work

\begin{tabular}{|c|c|c|}
\hline Property & Sand & Activated carbon \\
\hline $\mathrm{d}_{\mathrm{p}}(\mu \mathrm{m})^{1}$ & 120 & 110 \\
\hline$\rho_{\mathrm{s}}\left(\mathrm{kg} / \mathrm{m}^{3}\right)^{2}$ & 2350 & 1300 \\
\hline$\varepsilon_{\mathrm{p}}(--)^{3}$ & 0.7 & 0.66 \\
\hline Pore diameter $(\mathrm{nm})$ & 8.5 & 9.1 \\
\hline $\mathrm{S}_{\mathrm{BET}}\left(\mathrm{m}^{2} / \mathrm{g}\right)^{4}$ & 486 & 1864 \\
\hline Contact angle $\left({ }^{0}\right)$ & 43 & 89.3 \\
\hline
\end{tabular}

1- Measured using Beckman coulter LS 200.

2- Particle density measured using AccuPyc 1330 Pycnometer from micromeritics

3- Pore volume measured using SA 3100 from Beckman Inc.

4- BET area measured using SA 3100 from Beckman Inc.

5- Contact angle measure by VCA Optima from ACT products Inc

Table 2 Physical properties of the fluids used (at $25^{\circ} \mathrm{C}, 1 \mathrm{bar}$ )

\begin{tabular}{|c|c|c|c|c|}
\hline fluid & $\rho_{\mathrm{G}}\left(\mathrm{kg} \cdot \mathrm{m}^{-3}\right)$ & $\mu_{\mathrm{L}}(\mathrm{Pa} . \mathrm{s})$ & $\sigma_{\mathrm{L}}\left(\mathrm{mN} \cdot \mathrm{m}^{-1}\right)$ & $\rho_{\mathrm{L}}\left(\mathrm{kg} \cdot \mathrm{m}^{-3}\right)$ \\
\hline Air & 1.24 & ------- & ------- & ------ \\
\hline $\mathrm{CO}_{2}$ & 1.904 & -------- & ------ & ----- \\
\hline water & ------ & $\left(1 \times 10^{-3}\right)^{\mathrm{a}}$ & $(0.072)^{\mathrm{a}}$ & $(998)^{\mathrm{a}}$ \\
\hline $0.15 \mathrm{M} \mathrm{NaCl}$ & ------ & $\left(1 \times 10^{-3}\right)^{\mathrm{b}}$ & $(0.071)^{\mathrm{c}}$ & $(1004)^{\mathrm{d}}$ \\
\hline
\end{tabular}

(a) Vandu and Krishna (2004); (b) Ozbek et al. (1977); (c) Mortimer (2008); (d) Perry (1963)

\section{Results and discussion}

\section{Gas holdup}

\section{Effect of electrolyte}

The variation of gas holdup against superficial gas velocity is shown in Figure 3 with and without the presence of electrolyte respectively. As expected, the gas holdup in the presence of electrolyte is higher compared to distilled water. This increase is attributed to the existence of surfactants which affect the bubble generation process, enhancing the induction of small bubbles and hindering coalescence which influences the rising velocity of bubbles. The rising velocity of a single bubble is reduced and as a result the gas holdup is increased. This observation is in agreement with (Ruthiya et al., 2006).

\section{Effect of particles concentration and electrolyte}

Figures ( $4 \& 5$ ) illustrate the variation of gas holdup in the existence of electrolyte and different concentrations of sand and activated carbon particles respectively. As can be seen, the gas holdup rates increased with the particles loading at low solid concentration $\mathrm{C}=(0-3) \% \mathrm{v} / \mathrm{v}$, and decreased at higher concentration, $\mathrm{C}>3 \% \mathrm{v} / \mathrm{v}$ for both carbon and sand particles. This influence of particles loading on the gas holdup is motivating, since it points out the existence of two contending mechanisms. First mechanism is the tendency of fine particles to rupture the gas-liquid interface of the bubble causing it to breakdown into smaller bubbles. With smaller bubbles the reduction of bubble rise velocity outcomes in greater gas voidage. The second mechanism is to raise the viscosity of the slurry which enhances the bubble coalescence and gives increasing to both bubble volume and rise velocity of bubbles and as a result the gas holdup is reduced. As can be seen the reduction rate of gas holdup with increasing of

solid loading in the heterogeneous regime is less than the reduction rate of gas holdup in the transition regime. The observation is in agreement with the results of (Krishna, 2000).

\section{Influence of solid surface nature}

Relying on the interfacial characteristics of the gasliquid-solid system, particles tend for increasing or decreasing their concentration close to the gas-liquid interface. The precipitation at the surface of bubbles influences the slip boundary condition. The surface stability results more drag and less rise velocity. Figures ( $4 \& 5$ ) depict the effect of solid surface nature (i.e., sand and activated carbon) on gas holdup. As can be seen, these two types of particles have different effects on gas holdup. Carbon particles increase the gas holdup in the SBC whereas sand particles decrease the gas holdup. This behavior of $\mathrm{AC}$ particles may be attributed to the adhesion of some microbubbles generated with micro porous gas sparger-of volume smaller than AC particles to the lyophobic surface. The adhesion of bubble on AC particles leads to a reduction in the particle density. This phenomenon leads to increase in bed expansion which makes smaller gas holdup compared with lyophilic 
particle system (i.e., sand in our present study). For bubbles of volume larger than hydrophobic particles(i.e., $\mathrm{AC}$ in our present study), a different phenomenon occurs which is the adhesion of the hydrophobic AC particles on the bubble-liquid interface causes higher drag, and consequently lower rise velocity of bubbles leading to an increase in gas holdup. These results suggest that the degree of hydrophobicity matters. Our results were also observed by (Tsutsumi et al., 1991; Kluytmans et al., 2001).

\section{Critical values}

Every flow mode supplies various phase manner and blending features. If the bubble swarm velocity, $\mathrm{u}_{\mathrm{swarm}}$ $=\mathrm{u}_{\mathrm{g}} / \varepsilon_{\mathrm{g}}$, are plotted against the superficial gas velocity, the relative minima in the curve may be taken to indicate the transition point of the studied regime (Krishna, 2000). Figures 6,7, and 8 plot the effect of electrolyte-free solid, electrolyte-sand, and electrolyte-activated carbon on critical values of gas velocity respectively. As expected, all combinations used showed an impact on the transition point of the system in the following order, $u_{\mathrm{el}}>\mathrm{u}_{\mathrm{di}}>\mathrm{u}_{\mathrm{AC}}>$ $\mathrm{u}_{\mathrm{sa}}$.. This may be attributed to the adhesion of the hydrophobic AC particles on the bubble-liquid interfaced causes higher drag, and consequently lower rise velocity of bubbles leading to an increase in gas holdup. Hydrophilic silica particles on the contrary decrease the regime transition point and also the gas hold-up. It was found that for low solid content, $\mathrm{C} \leq 3 \% \mathrm{v} / \mathrm{v}$, the solid load has a negligible effect on transition velocity with lower values of bubble swarm velocity. Otherwise, at more loading, $\mathrm{C}>3 \% \mathrm{v} / \mathrm{v}$, a gradual reduction in stability of bubbly flow regime took place. Table 3 shows a quantitated presentation of transition velocity as function

of solid loading for carbon and sand particles according to Figures 7 and 8 . Table 3 depicts the predominant effect of hydrophobic particles on the stability of bubbly flow regime over that of hydrophilic ones.

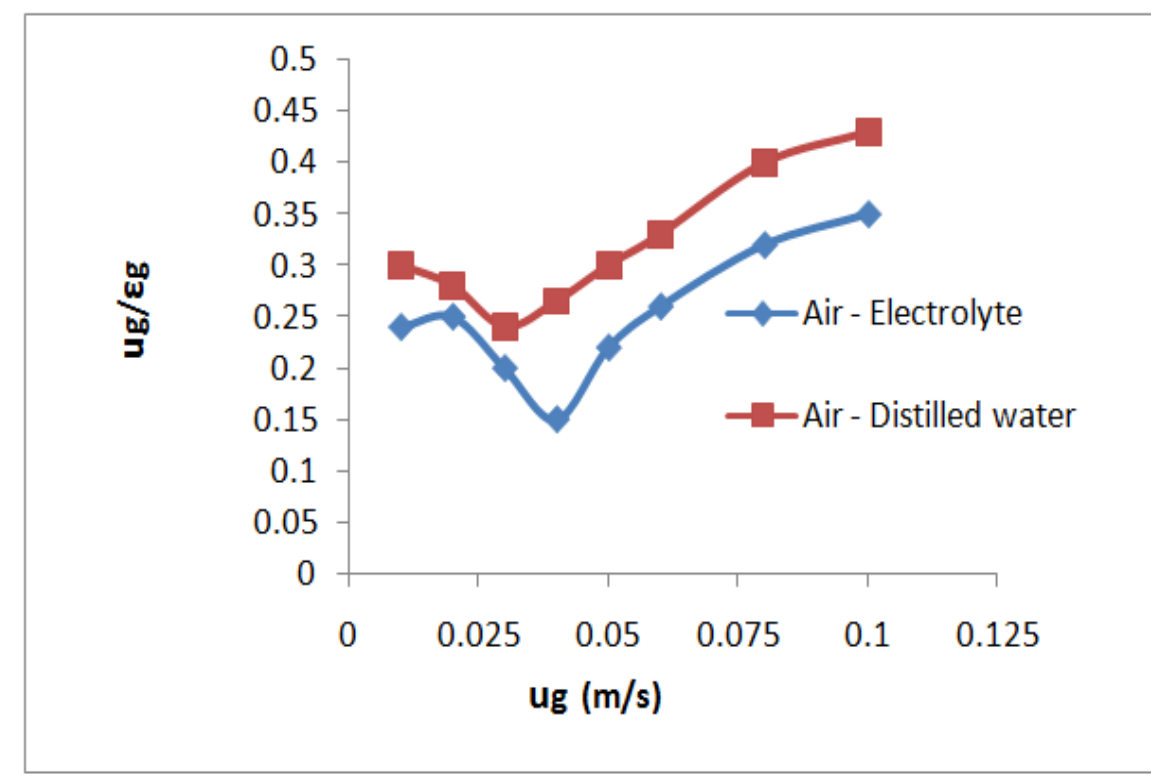

Figure (3): Variation of gas holdup vs. superficial gas velocity of solid free system 


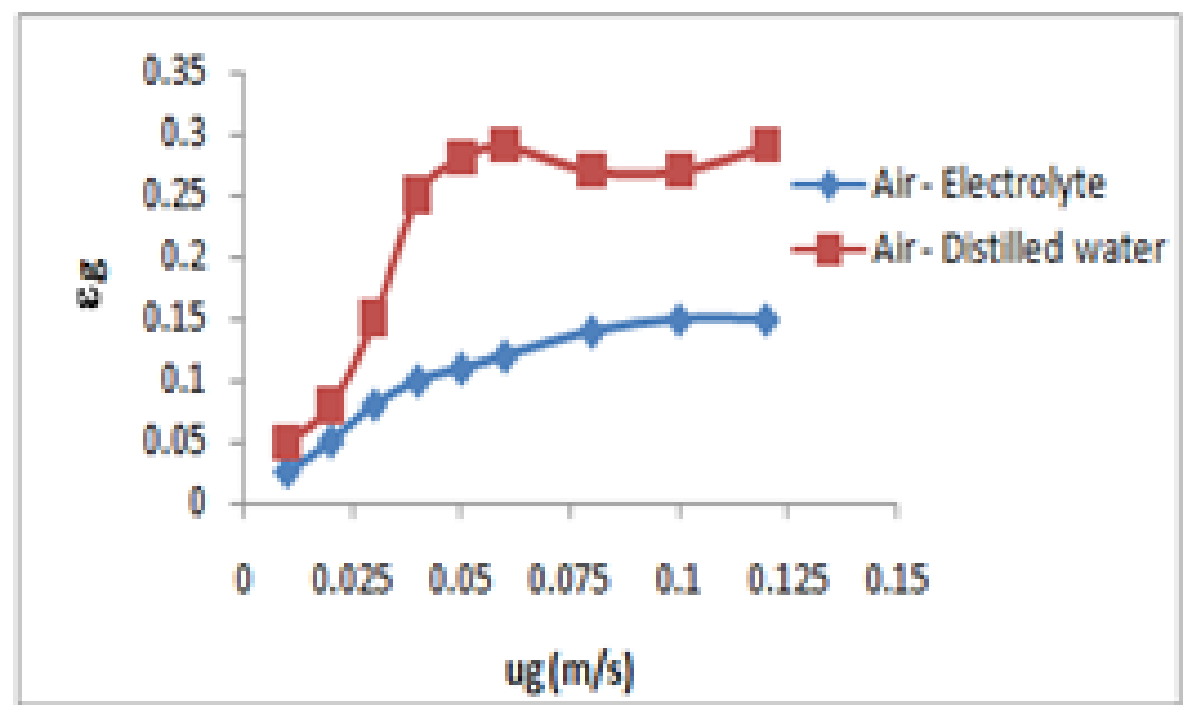

Figure (4): Variation of gas holdup vs. superficial gas velocity at different solid concentrations of sand particles

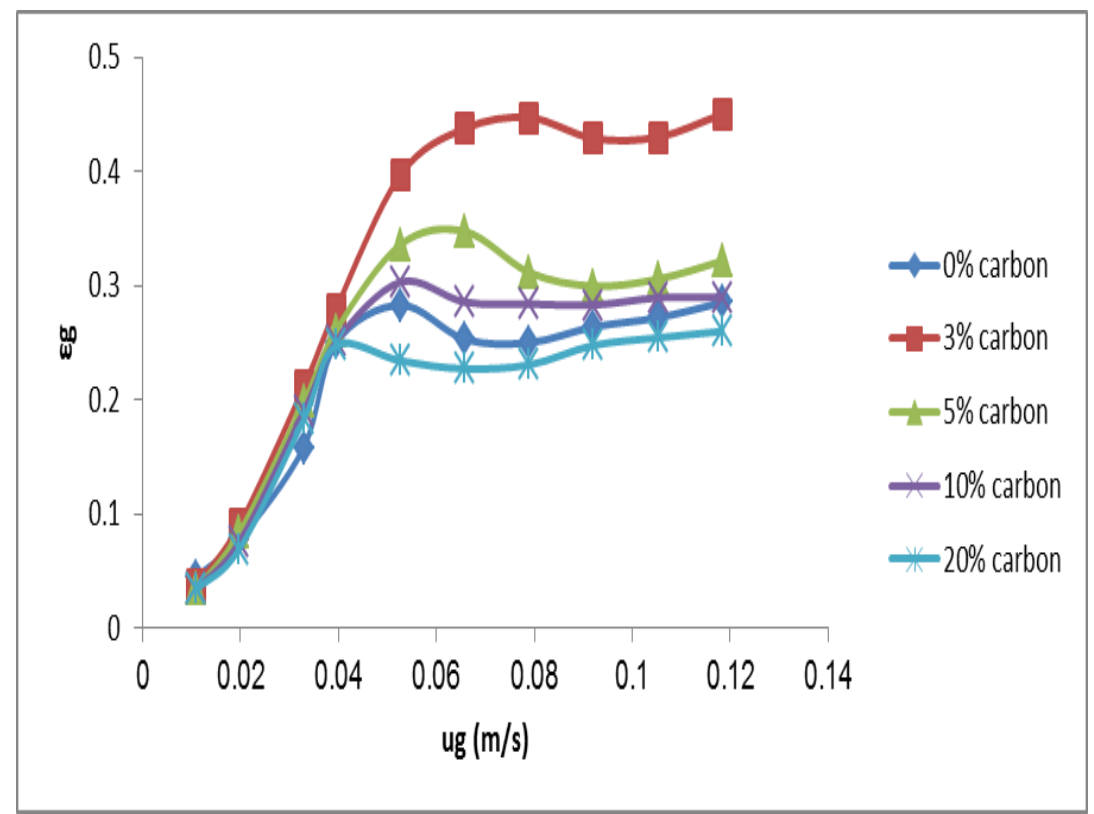

Figure (5): Variation of gas holdup vs. superficial velocity at different solid concentration of carbon particles 


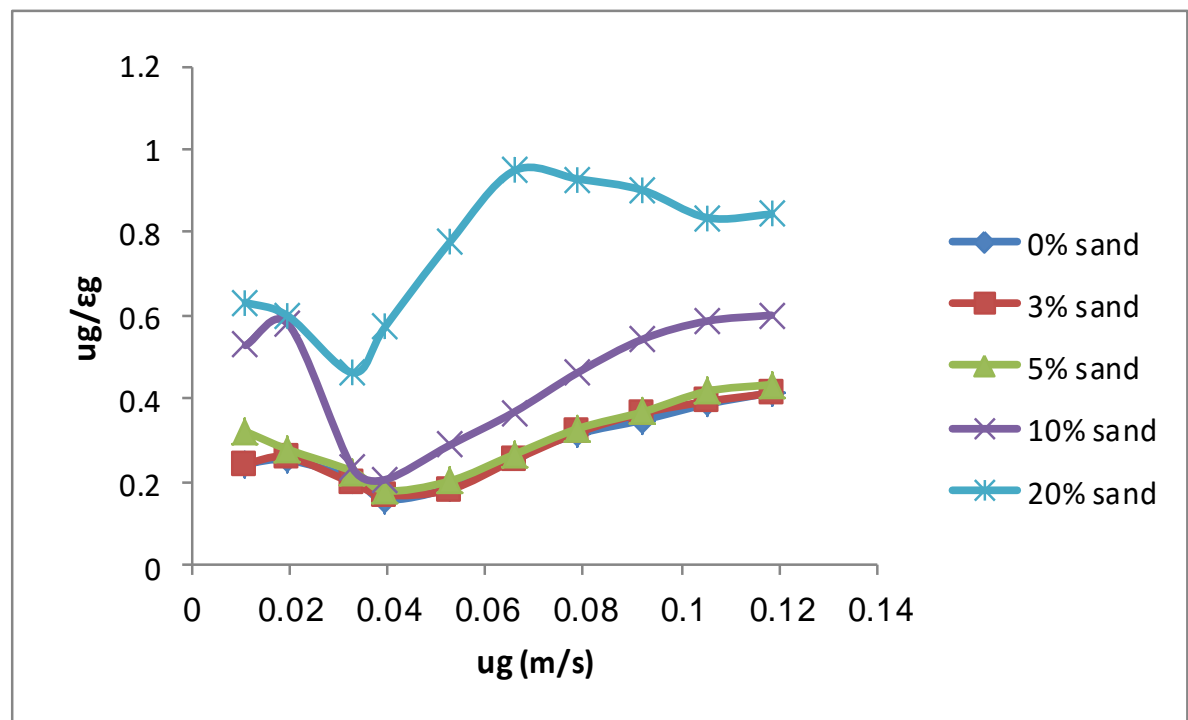

Figure (6): Variation of bubble swarm velocity vs. superficial gas velocity for solid free system

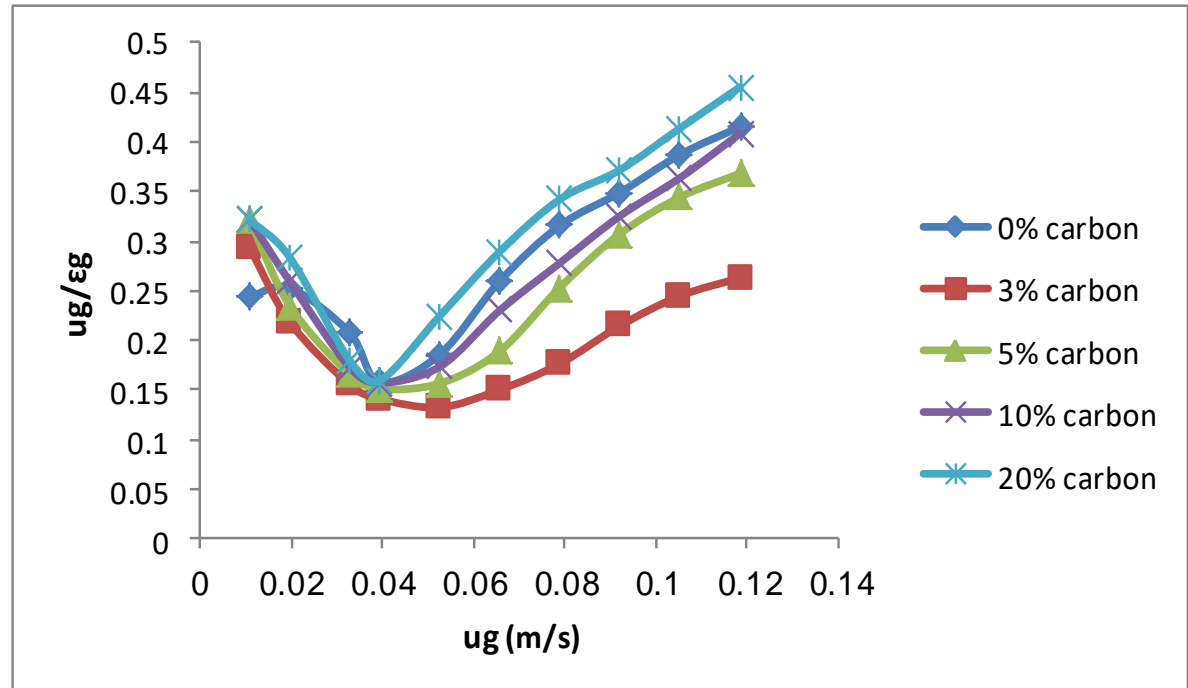

Figure (7): Variation of bubble swarm velocity vs. superficial gas velocity at different solid concentrations of sand particles 


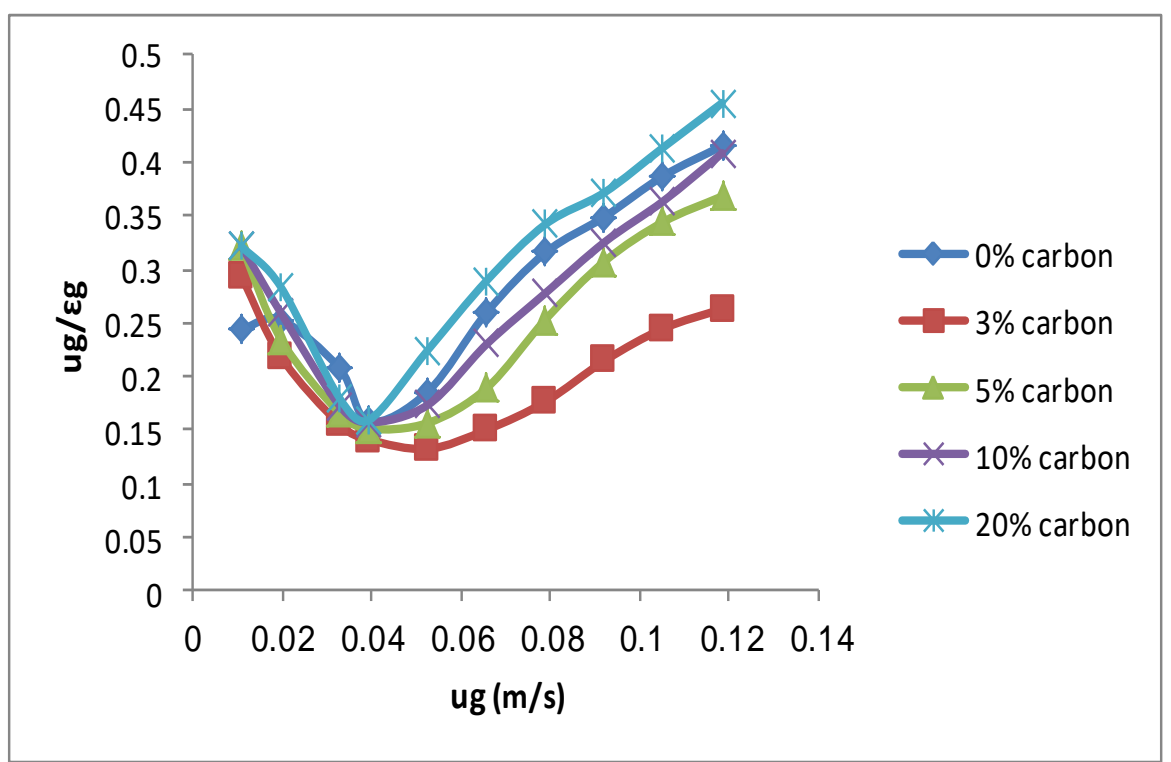

Figure (8): Variation of bubble swarm velocity vs. superficial gas velocity at different solid concentrations of carbon particles

Table 3 Effect of solid loading of wettable and non-wettable particles on critical gas velocity

\begin{tabular}{|c|c|c|}
\hline Solid loading(\%v/v) & $\begin{array}{c}\text { Critical gas velocity }(\mathrm{m} / \mathrm{s}) \\
\text { for sand particles }\end{array}$ & $\begin{array}{c}\text { Critical gas velocity(m/s) } \\
\text { for AC particles }\end{array}$ \\
\hline 0 & 0.0526 & 0.0526 \\
\hline 3 & 0.0526 & 0.0789 \\
\hline 5 & 0.0485 & 0.0657 \\
\hline 10 & 0.0394 & 0.0586 \\
\hline 20 & 0.0328 & 0.0394 \\
\hline
\end{tabular}

\section{Mass Transfer Coefficient}

A typical measurement at both optical fibers (OFPs), P1 and $\mathrm{P} 2$ when a bubble is crossing by can be seen at figure 9. The two signals represent responses of the upper and lower receiving fibers respectively. When a bubble move facing probe, a small fraction of light is reflected this gives a low voltage signal. By analyzing the time-averaged of each signal, the time lag between the signals can be determined by using a polynomial fit to estimate the minimum point of voltage and equation (6) can be used to determine the bubble velocity. To get accurate average properties of bubbles, a long period of measurement was carried out. Results for AC and sand particles at solid loading of $3 \% \mathrm{v} / \mathrm{v}$ are outlined in Table 4. Length of the bubble can be obtained from the time of contact of the bubble with any of the fibers, and by utilizing equation (6) along with the corresponding bubble rise velocity which listed in Table 3 . Size of the bubble was determined by applying eqn. (7) with the measured length. Table 3 shows also the size of the bubbles corresponding to their rise velocities. The OFPs records of the relatively small size of the bubbles at the point where the probe tip was located is consistent with the relatively low values of rise bubble velocity measured. Data outlined in Table 4 confirms the predominant effect of hydrophobic particles (i.e., AC) on size of the bubbles generated in the slurry bed and consequently on the gas holdup. Experimental results of Figure 10 show that the probe can also generate additional useful data, such as the distribution of the bubbles along the bed cross section in various operating conditions. Discreet regions can be seen in the histogram of Figure 10 this was attributed to crossing the light of the optical probes by solid particles. Figure 11 plots a comparison between $\mathrm{k}_{\mathrm{L}}$ a measured experimentally (eq. 8) and $\mathrm{k}_{\mathrm{L}}$ a predicted (eq.3). It is clear that by means of the OPFs technique the $\mathrm{k}_{\mathrm{L}}$ a values can be estimated reasonably well (within an error of $\pm 18 \%$ ). 


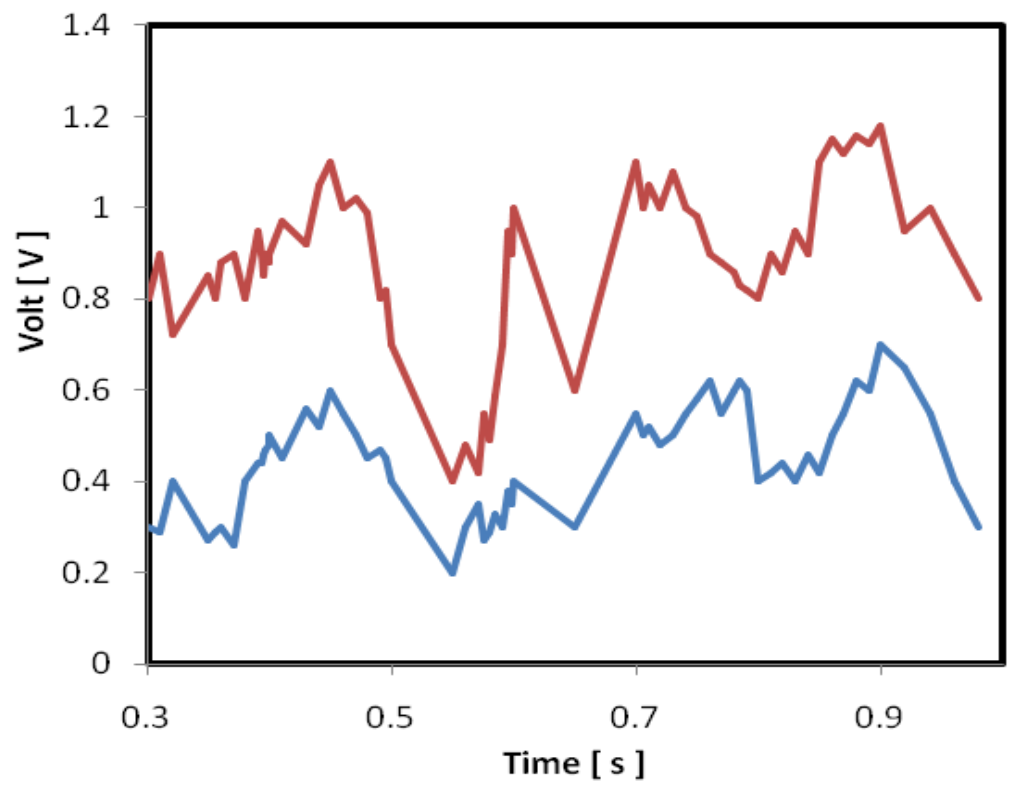

Figure (9): Output voltage measurements against time at bottom probe (upper signal) and top probe (lower signal

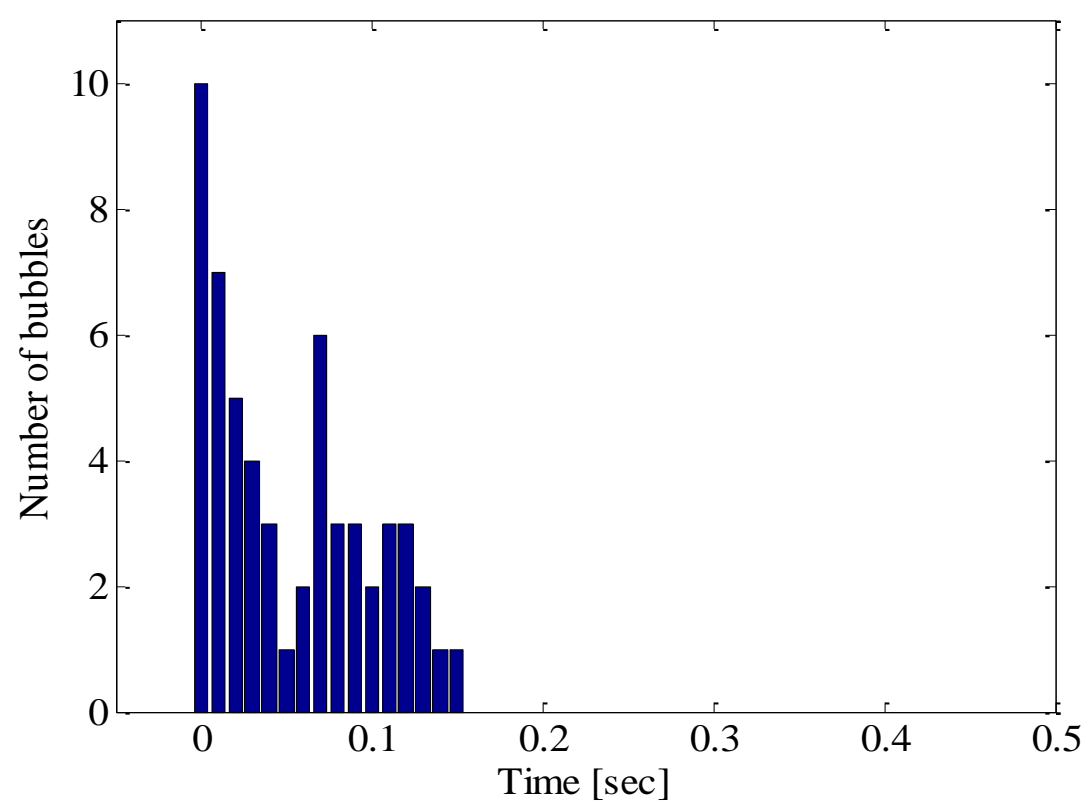

Figure (10): Histogram of bubbl measurements in slurry bed (solid phase is AC particles) 


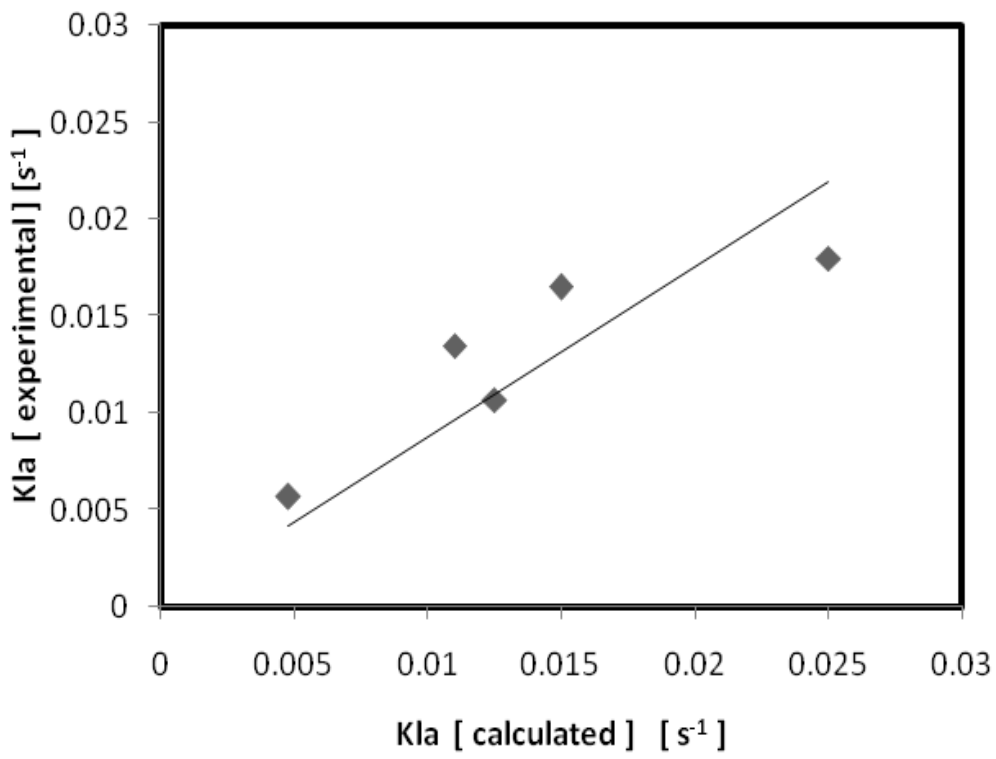

Figure (11): Experimentally measured against theoretical values of $\mathrm{k}_{\mathrm{L} . \mathrm{a}}$ (solid phase is AC particles).

Table 4 Set of measured time lag, bubble velocities and bubble size for AC and sand particles

\begin{tabular}{|c|c|c|c|c|c|}
\hline \multicolumn{2}{|c|}{ AC particles } & \multicolumn{3}{c|}{ Sand particles } \\
\hline $\begin{array}{c}\text { Time lag }(\mathrm{i}) \\
(\mathrm{sec})\end{array}$ & $\begin{array}{c}\text { Bubble velocity }\left(\mathrm{u}_{\mathrm{b}}\right) \\
(\mathrm{cm} / \mathrm{s})\end{array}$ & $\begin{array}{c}\text { Bubble size } \\
\left(\mathrm{d}_{\mathrm{b}}\right)(\mathrm{cm})\end{array}$ & $\begin{array}{c}\text { Time lag } \\
(\mathrm{i})(\mathrm{sec})\end{array}$ & $\begin{array}{c}\text { Bubble } \\
\text { velocity }\left(\mathrm{u}_{\mathrm{b}}\right) \\
(\mathrm{cm} / \mathrm{s})\end{array}$ & Bubble size $\left(\mathrm{d}_{\mathrm{b}}\right)(\mathrm{cm})$ \\
\hline 2.81 & 4.53 & 0.166 & 2.04 & 5.21 & 0.24 \\
2.09 & 5.16 & 0.129 & 1.92 & 5.84 & 0.35 \\
1.82 & 6.27 & 0.49 & 1.78 & 6.85 & 0.71 \\
1.75 & 7.11 & 0.78 & 1.71 & 7.96 & 1.14 \\
1.64 & 8.02 & 0.97 & 1.52 & 8.97 & 1.37 \\
\hline
\end{tabular}

\section{$\mathrm{CO}_{2}$ Removal}

Figures $12 \& 13$ plot the performance of a batch slurry reactor in which a stream of pure gaseous $\mathrm{CO}_{2}$ was bubbled through a bulk of $0.15 \mathrm{M} \mathrm{NaCl}$ solution with different loadings of sand and carbon particles respectively. Samples for analysis were taken after one hour period of each run to reach steady state conditions. As can be seen from Figures 12 and 13, the conversion increased linearly in a steep rate until a relative maxima was reached, after then, $\mathrm{CO}_{2}$ conversion started to decrease slightly. It is worth to note that, for each solid loading, the superficial gas velocity corresponding to maximum conversion obtained was approximately equal to the critical gas velocity estimated from Figures $7 \& 8$. This suggested that maximum $\mathrm{CO}_{2}$ removal could be obtained at the boundaries of the bubbly-transition regimes.

The trend in slight decrease of conversion at higher gas velocity may be attributed to the effect of bubble dynamics in turbulent regime. Large bubbles generated in the turbulent regime have higher rise velocity, and consequently short contact time with liquid solution. Figures $12 \& 13$ depict the effect of particle hydrophobicity on $\mathrm{CO}_{2}$ removal. As can be seen, slurry reactor loaded with non-wettable particles (i.e., AC) characterized by higher conversions of $\mathrm{CO}_{2}$. This is mainly due to the surface nature and physical properties of AC particles which are presented in Table 1. Mass transfer experiments were carried out with pure gaseous $\mathrm{CO}_{2}$ showed a behavior of removal in the same trend of increasing gas holdup with gas velocity. A noticeable removal of gaseous pollutants was observed for hydrophobic particles at solid loading of $3 \% \mathrm{v} / \mathrm{v}$.

\section{Empirical correlation}

From the experimental results of $\mathrm{CO}_{2}$ removal, the following empirical correlation was suggested. Coefficients which were evaluated employing the

technique of regression analysis are demonstrated in Table (5).

$\mathrm{CO}_{2}$ conversion $=\mathrm{a}_{0} \mathrm{C}^{\mathrm{a} 1} \mathrm{ug}^{\mathrm{a} 2}$ 


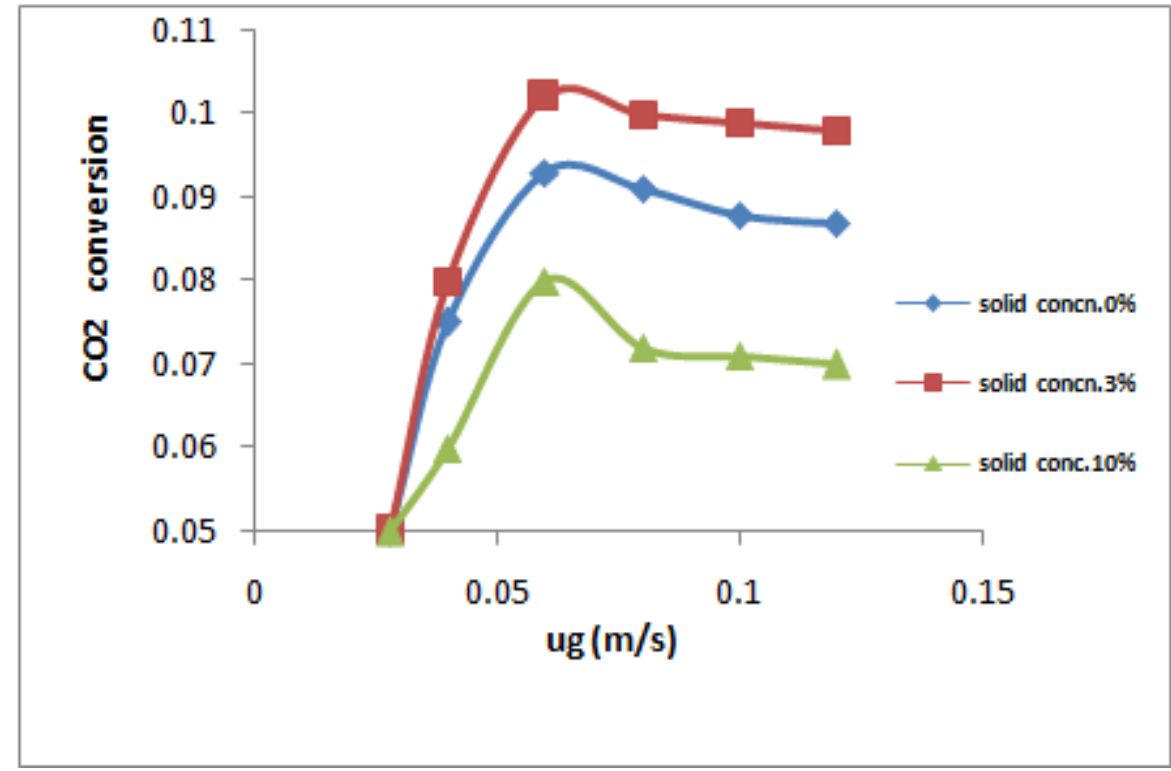

Figure (12): Effect of gas velocity on $\mathrm{CO}_{2}$ concentration at various loadings of sand particles

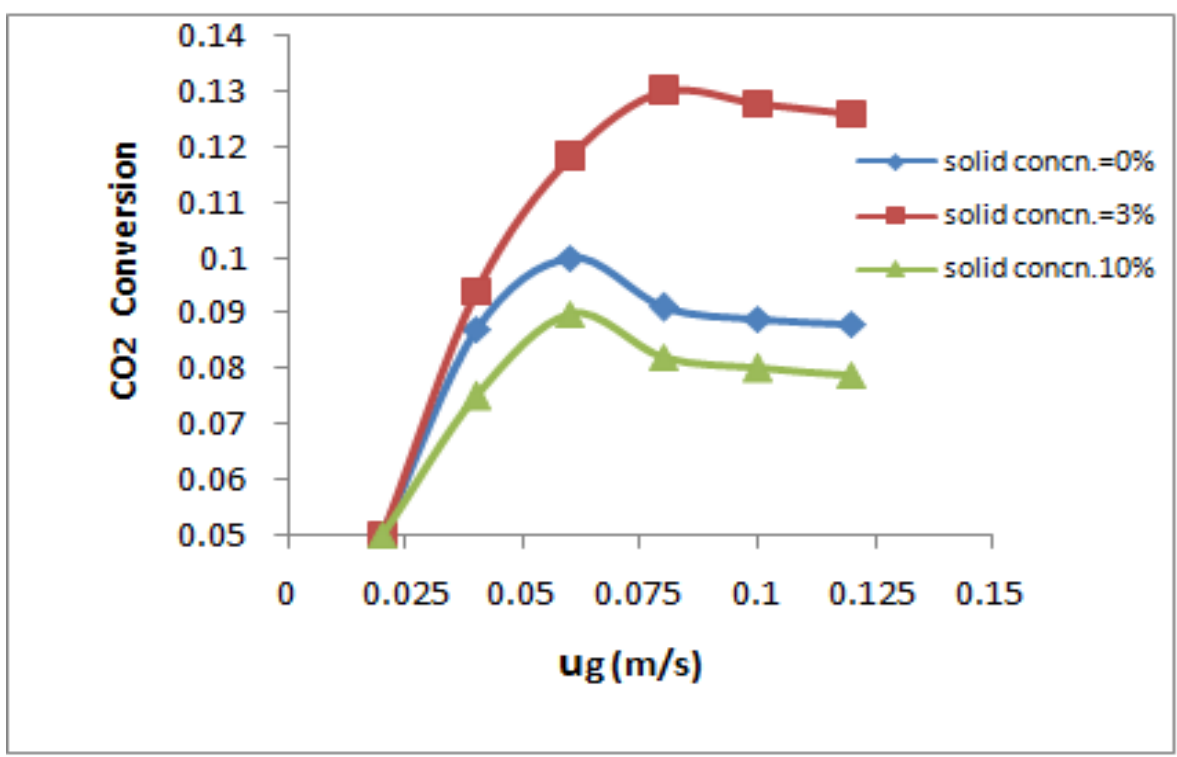

Figure (13): Effect of gas velocity on $\mathrm{CO}_{2}$ concentration at different loading of $\mathrm{AC}$ particles

Table 5 Statistical Evaluation of Fitting the Experimental Data with equation (10) 


\begin{tabular}{|c|c|c|c|c|c|}
\hline \multicolumn{7}{|c|}{ For sand } \\
\hline & $\mathrm{a}_{0}$ & $\mathrm{a}_{1}$ & $\mathrm{a}_{2}$ & $\begin{array}{c}\text { Correlation } \\
\text { Factor }\left(\mathrm{R}^{2}\right)\end{array}$ & variance \\
\hline $3 \% \mathrm{v} / \mathrm{v}$ & 0.267099 & -0.573761 & 1.115153 & 0.983 & 0.967 \\
\hline $10 \% \mathrm{v} / \mathrm{v}$ & 0.151108 & -0.212422 & 0.698649 & 0.97 & 0.94 \\
\hline \multicolumn{6}{|c|}{ For AC } \\
\hline $3 \% \mathrm{~V} / \mathrm{v}$ & 0.12802 & -1.13258 & 1.42051 & 0.9532 & 0.908 \\
\hline $10 \% \mathrm{v} / \mathrm{v}$ & 0.243139 & -0.241215 & 0.896222 & 0.9849 & 0.97 \\
\hline
\end{tabular}

\section{Conclusions}

The present work demonstrates and confirms the following,

(i) The present study shows a noticeable effect of catalyst carriers on the hydrodynamics and mass transfer rate in a slurry reactor.

(ii) The addition of active carbon, or silica particles at a solid loading $\mathrm{C} \leq 3 \% \mathrm{v} / \mathrm{v}$ to an aqueous solution of electrolyte, stabilizes the gas bubbles.

(iii) It was found that catalyst supports (i.e., silica, and activated carbon), at concentrations greater than (3 $\% \mathrm{v} / \mathrm{v})$ reduce the gas hold-up and shift the point of transition from homogeneous to heterogeneous flow regime to a lower gas velocity.

(iv) Hydrophobic particles (i.e., AC particles) offers more gas holdup than hydrophilic ones (i.e., silica).

(v) Experimental results show that the optical fiber probe is valid to use in slurry bubble column and can also generate useful data such as bubble rise velocity and bubble distribution.

(vi) The coefficient of mass transfer at liquid side can be reasonably estimated by optical fiber probes technique.

(vii) Mass transfer experiments were carried out with gaseous $\mathrm{CO}_{2}$ showed a behavior of removal in the same trend of increasing gas holdup with gas

velocity. A noticeable removal of gaseous pollutants was observed for AC particles at solid loading of $3 \%$ $\mathrm{v} / \mathrm{v}$.

\section{Acknowledgement}

The authors are thankful to the Chemical Engineering Department- University of Technology-Baghdad, for providing space and facilities to carry out this work.

\section{Nomenclature}

a interfacial area per unit $\left(\mathrm{cm}^{-1}\right)$

a0 constant in equation (10)

a1 power in equation (10)

a2 power in equation (10)

A reactor cross sectional area $\left(\mathrm{cm}^{2}\right)$

C solid concentration $(\% \mathrm{v} / \mathrm{v})$.

$\mathrm{C}_{0}$ parameter in equation (2)
$\mathrm{C}_{1} \quad$ parameter in equation (2)

$\mathrm{C}_{\mathrm{L}} \quad$ concentration of solute $\left(\mathrm{kgm}^{-3}\right)$

$\mathrm{C}_{\mathrm{L}^{*}} \quad$ concentration of solute at equilibrium $\left(\mathrm{kgm}^{-3}\right)$

$\mathrm{d}_{\mathrm{b}} \quad$ diameter of bubble $(\mathrm{cm})$

$\mathrm{D}_{\mathrm{L}} \quad$ molecular diffusivity $\left(\mathrm{cm}^{2} \cdot \mathrm{s}^{-1}\right)$

Eo Eötvös number

$f_{B} \quad$ bubble formation frequency

$h$ height of an ellipsoidal bubble $(\mathrm{cm})$

$\mathrm{H}_{\mathrm{D}} \quad$ height of dispersed slurry mixture $(\mathrm{cm})$

$\mathrm{H}_{\mathrm{L}}$ height of clear liquid $(\mathrm{cm})$

$\mathrm{k}_{\mathrm{L} . \mathrm{a}} \quad$ coefficient of mass transfer at liquid-side $\left(\mathrm{s}^{-1}\right)$

$l \quad$ ellipsoidal bubble length $(\mathrm{cm})$

$\mathrm{S}_{\mathrm{B}}$ bubble surface $\left(\mathrm{cm}^{2}\right)$

$\mathrm{t}$ time (s)

$\mathrm{u}_{\mathrm{g}} \quad$ superficial gas velocity $\left(\mathrm{cm} . \mathrm{s}^{-1}\right)$

$\mathrm{u}_{\mathrm{AC}} \quad$ critical superficial gas velocity for AC- electrolyte system $\left(\mathrm{cm} . \mathrm{s}^{-1}\right)$

$\mathrm{u}_{\text {dis. }} \quad$ critical superficial gas velocity for free solid-distilled water system $\left(\mathrm{cm} \cdot \mathrm{s}^{-1}\right)$

$\mathrm{u}_{\mathrm{el}} \quad$ critical superficial gas velocity for free solidelectrolyte system $\left(\mathrm{cm} . \mathrm{s}^{-1}\right)$

$\mathrm{u}_{1} \quad$ superficial liquid velocity $\left(\mathrm{cm} \cdot \mathrm{s}^{-1}\right)$

$\mathrm{u}_{\mathrm{sa}}$. critical superficial gas velocity for sand-electrolyte system $\left(\mathrm{cm} . \mathrm{s}^{-1}\right)$

$\mathrm{z} \quad$ axial distance along the column $(\mathrm{cm})$

\section{Greek Letters}

$\varepsilon_{\mathrm{g}} \quad$ gas hold up (--).

$\mu_{\mathrm{L}} \quad$ viscosity of liquid ( $\left.\mathrm{kg} / \mathrm{m} . \mathrm{s}\right)$

$\rho_{\mathrm{g}} \quad$ density of gas $\left(\mathrm{kg} . \mathrm{m}^{-3}\right)$

$\rho_{\text {gref }}$ density of gas at standard conditions $\left(\mathrm{kg} \cdot \mathrm{m}^{-3}\right)$

$\rho_{\mathrm{L}} \quad$ density of liquid $\left(\mathrm{kg} \cdot \mathrm{m}^{-3}\right)$

$\sigma_{\mathrm{L}} \quad$ surface tension of liquid $\left(\mathrm{N} . \mathrm{m}^{-1}\right)$

\section{References}

[1].Abid, M. F., Hadi, A. A., Ahmed, S. M., Hydrodynamic Characteristics Effect of Foam Control in a Three Phase Fluidized Bed Column, Journal of Petroleum Research and Studies, 6, 158-185, (2012).

[2].Babadi, F., and B.,Farhanieh, Characteristics of heat and mass transfer in vapor absorption of falling film 
flow on a horizontal tube, International Communications in Heat and Mass Transfer, 9, 1253-1265 (2005).

[3].Chabot J., Lee S. L. P., Soria A., De Lasa H. I., Interaction between Bubbles and Fiber Optic Probes in a Bubble Column, Can J Chem Eng., 70, 61-68, (1992).

[4].Chan, I. E., Sisahtla, C., Knowlton, T.M., Effect of pressure on bubble parameters in gas-fluidized beds, Powder Technology, 53, 217- 245, (1987).

[5].Clift, R.; Grace, J. R. \& Weber, M., Bubbles, Drops and Particles, Academic Press, New York, U.S. A., (1978).

[6].Degaleesan, S., M. Dudukovic, and Y. Pan, Experimental study of gas-induced liquid-flow structures in bubble columns, AIChE J., 47, 19131931 (2001).

[7].Fan, L. S. \& Tsuchiya, K, Bubble Wake Dynamics in Liquids and Liquid-Solid Suspensions, Butterworth-Heinemann Series in Chemical Engineering, Stoneham, U.S.A. (1990).

[8].Fukuma, M.; Muroyama, K. \& Yasunishi, A., Properties of Bubble Swarm in a Slurry Bubble Column, J. Chem. Eng. Japan, 20, 28-33, (1987).

[9].Herbolzheimer, E., and I. Enrique, Slurry bubble column, Patent US RE39,073 E, Apr. 18, 2006.

[10]. Hikita,H., Asal, S., Tanigawa, K., Segawa, K., and Kitao, M., Gas hold-up in bubble column, Chem. Eng. J., 20, 59 (1980).

[11]. Hyndman, C. L., Larachi, F., and Guy, C., Understanding gas-phase Hydrodynamics in Bubble column: a convective model based on kinetic theory, Chem. Eng. Sci. 1, 52, 63 (1997).

[12]. Jamialahmadi, M., and Muller-Steinhagen, H., Effect of solid particles on gas hold-up in bubble columns, Candian Journal of Chemical Engineering, 69, 390-393(1991)

[13]. Jiang, P.; Lin, T.-J., Luo, X. \& Fan, L.-S., Flow Visualization of High Pressure (21 MPa) Bubble Columns: Bubble Characteristics, Trans. Inst. Chem. Eng., 73, 269-274 (1995).

[14]. Katsuaki, I., Tong-Yen, W., K., Koide, and K., Hirodhi, , The behavior of suspended solid particles in the bubble column, JCEJ, 1, 153-158 (1967).

[15]. Krishna, R., De Stewart, J. W. A., Ellenberger, J., Martina, G. B., and Maretto, C., Gas hold-up in slurry bubble columns: Effect of column diameter and slurry concentrations, AIChE J., 43, 311 (1997).

[16]. Krishna, R., A Scale-Up Strategy for a Commercial Scale Bubble Column Slurry Reactor for FischerTropsch Synthesis, Oil and Gas Science and Techn.Rev. IFP, 55, 359-393 (2000).

[17]. Kluytmans, H. J., Berend G. M. , Wachem, V., Kuster F. M., and Schouten J.C., Gas Holdup in a Slurry Bubble Column: Influence of Electrolyte and Carbon Particles, Ind. Eng. Chem. Res.,40,5326-5333, (2001).

[18]. Letzel,H.M., J.C. Schouten, R. Krishna, C.M. van den Bleek, Gas holdup and mass transfer in bubble column reactors operated at elevated pressure. Chem. Eng. Sci., 54: 2237-2246 (1999).

[19]. Liu, J., J.R. Grace, X. Bi., Novel Multifuncyional Optical-Fiber Probe: I. Development and Validation. AIChE Journal, 49, 1405-1420 (2003a).

[20]. Liu, J., J.R. Grace, X. Bi., Novel Multifuncyional Optical-Fiber Probe: II. High-Density CFB Measurements. AIChE Journal 49-6 1421-1432 (2003b).

[21]. Mainland, M.E., J.R Welty, Use Of Optical Probes To Characterize Bubble Behavior In Gas-Solid Fluidized Beds, AIChE Journal, 41 , 223-228 (1995).

[22]. Mortimer, R. G., Physical Chemistry, $4^{\text {th }}$ edition, Elsevier Acadimic Press, Canada (2008).

[23]. Nedeltchev, S. \& Schumpe, A., Theoretical Prediction of Mass Transfer Coefficients in a Slurry Bubble Column Operated in the Homogeneous Regime, Chem. \& Biochem. Eng. Quarterly, Vol. 21, 327-334 (2007).

[24]. Nedeltchev, S.; Jordan, U. \& Schumpe, A., Correction of the Penetration Theory Applied to the Prediction of $k L a$ in a Bubble Column with Organic Liquids, Chem.Eng. Tech., 29, 1113-1117 (2006a).

[25]. Nedeltchev, S.; Jordan, U. \& Schumpe, A., A New Correction Factor for Theoretical Prediction of Mass Transfer Coefficients in Bubble Columns, J. Chem. Eng. Japan, 39, 1237-1242 (2006b).

[26]. Ozbek, H., J.A. Fair, and S. Phillips, Viscosity of Aqueous Sodium Chloride Solutions From $0-150^{\circ} \mathrm{C}$, Presented Part at the American Chemical Society 29th Southeast Regional Meeting,' Tampa, November 9-11, 1977

[27]. Perry, J.H., Chemical Engineering Handbook, $4^{\text {th }}$ edition, McGraw-Hill, Inc., NY (1963).

[28]. Pinset, B. R. W., L. Pearson, and F. J. W. Roughton, The kinetics combination of carbon dioxide with hydroxide ions, Trans .Faraday Soc., 52, 1512 (1956). 
[29]. Reid, R.C., and Sherwood, T.K., The properties of gases and liquids, $2^{\text {nd }}$ edition, McGraw-Hill, New York (1977).

[30]. Ruthiya, K.C., Schaaf, J., Kuster, F.M., Schouten, J.C., Influence of Particles and Electrolyte on Gas Hold-Up and Mass Transfer in a Slurry Bubble Column, International Journal of Chemical Reactor Engineering, 4,( 2006).

[31]. Ruzicka,M. C., Mena, P.C., Rocha, F.A., and Drahos, J., Effect of solids on homogeneousheterogeneous flow regime transition in bubble columns, Chem. Eng. Sci., 60, 6013-6026 (2005).

[32]. Sada, E., Katoh, S., and Yoshil, H., Performance of the gas-liquid bubble column in molten salt systems, Ind. Eng. Chem. Process Des .Dev., 23, 151(1984)

[33]. Shah, Y. T., Kellar, B. G., Godbole, S. P., and Deckwer, W. D., Design parameters estimation for bubble column reactors, AIChE J., 28,353-379, (1982).

[34]. Sheikh, A., and Al-Dahhan, M., Characterization of the hydrodynamic flow regime in bubble columns via computed tomography. Flow Measurement and Instrumentation, 16, 91-98, (2005).

[35]. Sheikh, A., and Al-Dahhan, M.,A Review on Flow Regime Transition in Bubble Columns, International Journal of Chemical Reactor Engineering, Vol.5, Review R1, 1-68, (2007).

[36]. Tsutsumi, A., A., Ghosh Dastidar and L., Fan, Characteristics of Gas-Liquid- Solid Fluidization with Nonwettable Particles, AIChE Journal, 37, 951-952.(1991).

[37]. Vandu, C. O. and Krishna R., Gas Hold and Volumetric Mass Transfer Coefficient in a Slurry Bubble Column, Chem. Eng. Tech., 26, 779-782 (2003).

[38]. Vandu, C.O and Krishna R., Volumetric mass transfer coefficients in slurry bubble columns operating in the churn-turbulent regime, Chemical Engineering and Processing, 43, 987-995 (2004).

[39]. Vial, C., Poncina, S., Wild, G., and Midox, N., Experimental and theoretical analysis of the hydrodynamics in the riser of an external loop airlift reactor, Chem. Eng. Sci., 57, 4745 (2002).

[40]. Wang, T. F., Wang, J. F., Zahao, B., Ren, F., and Jin, Y., Local hydrodynamics in external loop airlift slurry reactors with and without resistance- regulating element, Chem. Eng. Commun., 191, 1024 (2004).

[41]. Wilkinson, P. M.; Spek A. P. \& Van Dierendonck, L. L., Design Parameters Estimation for Scale-Up of HighPressure Bubble Columns, AIChE J., 38, 544554(1992).

[42]. Zahradink, J., and Fialova,M., The effect of bubbling regimes on gas and liquid phase mixing in bubble column reactors, Chem. Eng. Sci.,51, 2491 (1996).

[43]. Zuber, N., and Findlay, J. A., Average volumetric concentration in two- phase flow systems, J. Heat Transfer, 87, 453 (1965). 